\title{
DE MUROS INTRANSPONÍVEIS A FRONTEIRAS TRANSITÁVEIS
}

\author{
From uncrossable walls to transitable borders
}

Juan Carlos Velasco*

\begin{abstract}
Resumen. A compreensão das fronteiras como dispositivos essencialmente obstrutivos, tal como transparece na imagem dos muros, representa apenas uma percepção simplista que, no entanto, tem sido amplamente disseminada. Fronteiras e muros não são duas maneiras de expressar um mesmo conceito. Suas funções são distintas: as fronteiras, diferentemente dos muros, não buscam primariamente impedir os intercâmbios, mas regular os trânsitos. No decorrer deste artigo são exploradas as razões normativas para o estabelecimento de um regime migratório solidário que ofereça uma alternativa à blindagem das fronteiras que atualmente predomina.
\end{abstract}

Palavras-chave: fronteiras; muros; políticas migratórias; nacionalpopulismo; fronteiras abertas.

\begin{abstract}
The understanding of borders as essentially obstructive devices, as reflected in the image of walls, represents only a simplifying perception that has nevertheless been successfully disseminated. Borders and walls are not two words for the same concept. The functions attributed to one and the other are different: the primary function of borders, unlike walls, is not to prevent exchanges, but to regulate transits. This article explores the normative reasons for establishing a supportive migration regime that offers an alternative to the current predominant border shielding.
\end{abstract}

Keywords: borders; walls; migration policy; national populism; open borders.

A proliferação ${ }^{1}$ de muros e outros tipos de barreiras em todo o planeta reabriu o debate, nunca resolvido, sobre a legitimidade que os Estados têm de fechar ou abrir as fronteiras ou, mais precisamente, se os Estados possuem o direito exclusivo de controlar o acesso de estrangeiros ao seu próprio território

\footnotetext{
Investigador Científico del Instituto de Filosofía del CSIC, Madrid. E-mail: jc.velasco@csic.es. Orcid: 0000-0002-5346-4429.

1 Este artigo foi elaborado no âmbito do projeto "Fronteras, democracia y justicia global" (PGC2018-093656-B-I00), financiado pelo Plan Estatal de I+D+i do Governo de Espanha, e do qual o autor é Investigador Principal.
} 
ou se essa é uma decisão que deve ser justificada perante todos os envolvidos, sejam eles membros ou não da comunidade política em questão (Abizadeh, 2008; Brezger, 2018). A doutrina jurídico-política dominante reconhece que o controle das fronteiras é parte do poder soberano dos Estados, que teriam o direito de determinar seus próprios limites e definir os critérios de pertencimento. Nesse sentido, costuma-se argumentar que, com vistas a manter seu bem-estar e sua própria identidade, algo ao qual todo povo constituído em um Estado teria direito, as sociedades dispõem do poder para limitar a imigração (Walzer, 1993, p. 44-74; Miller, 2005, 2016). A política de recepção de imigrantes estaria, portanto, subordinada aos interesses particulares de cada sociedade. No entanto, essa difundida concepção não encerra o debate. Os Estados não podem mais ignorar a dificuldade de compatibilizar a autoridade que cada país soberano possui de proteger suas fronteiras e o dever indeclinável de respeitar os direitos humanos. Os indivíduos são protegidos por serem pessoas, não por causa de sua nacionalidade, o que limita a autonomia dos governos, que são assim confrontados pelo desafio de proteger as fronteiras sem desproteger as pessoas.

Além do fato de que o fechamento completo das fronteiras seja uma mera ilusão, como comprovado pela maciça migração irregular (Pécoud, Guchteneire, 2006), uma abundante literatura tem destacado o status normativo problemático de alguns limites territoriais que não são apenas historicamente contingentes, mas, muitas vezes, são resultados de graves injustiças e irregularidades, tais como conquistas, colonizações, transferências sem consentimento ou compras ilegais de territórios (Foucher, 2012). Além da origem, podem ser questionadas algumas das funções estruturais que, na prática, são atribuídas às fronteiras, entre as quais cabe destacar o papel de demarcar oportunidades espacialmente diferenciadas entre as pessoas (Ypi, 2008, p. 395) e, dessa forma, consagrar as profundas desigualdades econômicas existentes entre os Estados e, em última instância, naturalizar as injustiças globais (Velasco, 2019). Essas formas de injustiça são perpetuadas pelo fato de que um número considerável de pessoas não têm possibilidades legais e efetivas de migrar para países com melhor qualidade de vida. Como consequência direta do fechamento das fronteiras, mesmo quando essas pessoas conseguem de fato migrar, geralmente o fazem em condições extremamente penosas.

Neste contexto, a obsessão pela segurança, pela estabilidade e pela manutenção do statu quo em nível global se torna completamente insuportável para os desfavorecidos. O acesso justo aos recursos da Terra e às inovações humanas não é uma simples possibilidade, e sim um imperativo para a sobrevivência pacífica da espécie. E a busca por modelos políticos, sociais e econômicos mais inclusivos e equitativos só será factível em escala global se o papel atribuído às fronteiras territoriais for substancialmente 
modificado. Visando oferecer uma alternativa, este artigo argumentará a favor da mudança de um modelo que interpreta as fronteiras como muros supostamente intransponíveis para outro que as concebe como locais de trânsito regulamentado. Após a experiência adquirida com a construção de milhares de quilômetros de muros, chegou a hora de refletir sobre as alternativas à dissuasão pelo terror e à blindagem das fronteiras, a única que até agora foi pautada, e pensar em soluções que sejam compatíveis com valores democráticos fundamentais, como a solidariedade e a justiça social.

\section{Fronteiras e discurso nacional-populista}

Até não muito tempo atrás, podia-se pensar, talvez ingenuamente, que com a globalização as fronteiras políticas acabariam sendo diluídas. Quando caiu o Muro de Berlim, em 1989, muitos entenderam que essa possibilidade estava muito mais próxima. O otimismo cosmopolita que apareceu ao final da Guerra Fria, ainda que de modo efêmero, deu asas a uma retórica idílica em torno do surgimento de "um mundo sem fronteiras" ${ }^{2}$. Difundiu-se, então, a ideia de que, à medida que a globalização avançasse, a relevância das fronteiras diminuiria. Não parece, no entanto, que desde então a história tenha trilhado esses caminhos, pois a verdade é que "os processos globalizantes dos últimos vinte anos levaram não à diminuição das fronteiras, mas à sua proliferação" (Mezzadra, Neilson, 2017, p. 84).

O historiador David Frye, que estudou em profundidade o tema da construção de muros em conexão com os grandes processos civilizatórios, infere que o mundo, nos primeiros anos deste novo milênio, entrou na Segunda Era dos Muros (Frye, 2019, p. 290-291). De uma perspectiva histórica, as recentes mudanças neste campo só podem ser comparadas com os tempos dos grandes impérios da Antiguidade. Desde o desmantelamento da Cortina de Ferro - e se passaram apenas trinta anos -, quase 30.000 km de novas fronteiras foram traçados como resultado do estabelecimento de novos Estados: cerca de 12.000 km na Europa e mais de 15.000 km na Ásia Central.

As fronteiras não apenas se proliferaram, mas também se fortificaram, visando impedir o fluxo de pessoas, algo que, como tal, não é parte intrínseca de seu sentido primário, que não é outro senão aquele da demarcação territorial, isto é, uma linha de delimitação entre as comunidades políticas. Embora, às vezes, não seja mais do que uma linha na areia, o traçado físico das

2 Depois do fim do bloco soviético e da bipolaridade geopolítica, a última década do século XX foi um período relativamente otimista em termos das possibilidades de intensificar a cooperação internacional para enfrentar os problemas globais (Vallet, David, 2012, p. 6), pelo menos em contraste com a desolação posterior causada pelos ataques de 11 de Setembro e, sobretudo, pela grande crise económica que começou em 2007-2008. Tais acontecimentos transformaram a confiança em pessimismo e desinteresse e, por vezes, também em um recuo unilateralista. 
fronteiras políticas serve para indicar o território onde é afirmada a jurisdição de cada Estado. As fronteiras transformam um espaço geográfico em um espaço político, delimitam os territórios a fim de estabelecer uma determinada ordem do mundo (Balibar, 2005). A compreensão das fronteiras como um dispositivo essencialmente obstrutivo, conforme explicitada na imagem dos muros, representa apenas uma percepção simplista que, no entanto, foi disseminada com sucesso. Fronteiras e muros não são duas maneiras de expressar um único conceito. Suas funções são claramente distintas no que diz respeito à circulação de pessoas e de bens: a função primária das fronteiras, diferentemente dos muros, não é impedir os intercâmbios, e sim regular o trânsito. É necessário, então, explicar como se produziu essa mudança de sentido sobre as fronteiras.

É possível apresentar algumas hipóteses que permitam esclarecer o emaranhado ideológico, socioeconômico e cultural subjacente à mudança acima mencionada. Uma maneira plausível seria insistir que o discurso, na forma de preconceito hostil e de fabricação artificial de inimigos, precede a implementação de certas políticas. A manipulação da linguagem é uma das armas mais poderosas nas disputas cotidianas pela hegemonia tanto cultural como política. No caso das políticas de migração, observa-se também que a efetivação de medidas restritivas foi precedida pela disseminação de um discurso manifestamente antimigratório. Inicialmente, tratava-se de propagar uma linguagem, uma semântica e, em última instância, um novo quadro ideológico e conceitual; somente mais tarde se percebeu que o objetivo final não era outro senão construir um quadro mental politicamente explosivo que justificasse a implementação de regulamentações migratórias rigorosas e até virulentamente hostis (Bauman, 2016, p. 11-12).

Um árduo trabalho infiltrado nos meios de comunicação - tanto nos tradicionais quanto nas cada vez mais influentes redes sociais - prepara o terreno que sustentará um novo marco conceitual (Lakoff, 2007). No que diz respeito às migrações, nos últimos anos consolidou-se um marco discursivo que dá prioridade à identidade coletiva e à segurança nacional, de modo tal que a solidariedade e a justiça social transfronteiriças perdem totalmente seu valor. Este marco pode ser classificado como nacional-populista na medida em que defende a exaltação demagógica dos interesses nacionais (Eatwell, Goodwin, 2018), um marco que está sendo rapidamente assumido por diferentes grupos políticos. "Primeiro, os nossos (os nacionais)" ou "Mão pesada com os estrangeiros" são alguns dos lemas predominantes, expressões da polarização social gerada por essa ascendente tendência política que exacerba a distinção entre "nós" e "eles". Nesse marco, não cabe qualquer consideração acerca das contribuições relevantes que os imigrantes fazem para o bem-estar geral das sociedades receptoras, seja em termos demográficos, econômicos ou culturais. 
Os nacional-populismos, especialmente nos países mais prósperos, promovem explicitamente a disseminação do chauvinismo do bem-estar ${ }^{3}$. No modelo social que defendem, de certa forma, o ideal de solidariedade é mantido, materializado nas proteções fornecidas pelo Estado e configurado com um alcance estritamente nacional, mas agora reservado exclusivamente aos nativos. Diante de qualquer indício de hospitalidade cosmopolita, insiste-se no caráter necessariamente topológico ou situado dos bens sociais, que supostamente os impede de serem partilhados com os que vêm de fora (independentemente dos retornos financeiros de sua presença, isto é, sem sequer lhes dar a oportunidade de demonstrar que, com o seu esforço, qualificações e impostos podem contribuir significativamente para o bem-estar do país de acolhimento). Garantir esse tipo de sistema social fechado torna-se um objetivo que legitima a rejeição do estrangeiro e, com isso, a implementação de políticas migratórias restritivas.

Uma vez adotado esse novo marco ideológico, é fácil justificar o aumento do peso atribuído à função discriminatória das fronteiras, que se tornam linhas do território onde ocorre a classificação entre fluxos desejáveis e indesejáveis, entre mercadorias e seres humanos, através de dispositivos físicos ou administrativos. Os esforços são então direcionados no sentido de tentar conter os fluxos migratórios indesejados, sem considerar meios ou princípios. A polarização induzida leva à violência simbólica e, em última análise, à violência física. Assim, como solução mágica, propõe-se o fechamento das fronteiras e, como suposta panaceia, a ereção de mais muros e outros tipos de obstáculos. Não importa que levantá-los seja um esforço bastante ineficaz para atingir o objetivo expressamente declarado. Na realidade, é útil para aqueles que lucram com sua construção, manutenção e vigilância (Rodier, 2013), todo um conglomerado de elevados negócios que floresce na sombra do Estado (Andersson, 2014). E, aparentemente, também não importa muito que este procedimento seja muito pouco solidário com os deserdados do planeta, essa parte nem tão pequena da humanidade. As fronteiras fortificadas, sob a vã justificativa de garantir a integridade sociocultural do país ou de impedir novas formas de delinquência, mal podem esconder sua função de barreira contra os que fogem da miséria, das guerras, das tiranias, dos desastres naturais e de outras desgraças. Com esses elementos, que não atentam na construção do inimigo, constrói-se um discurso ideológico para oferecer aos cidadãos um culpado por seus males: as pessoas migrantes e os párias. Na verdade, se olharmos em detalhes, não é tanto questão de xenofobia, e sim de aporofobia: em geral, não se rejeita o estrangeiro, em geral, mas sim o pobre (Cortina, 2017).

\footnotetext{
3 A noção de chauvinismo do bem-estar foi cunhada por Jürgen Habermas (1998, p. 636-643) para explicar a difundida relutância das sociedades mais desenvolvidas em compartilhar as oportunidades e os direitos sociais de que desfrutam com as pessoas procedentes de países menos favorecidos.
} 


\section{Fronteiras fortificadas, um dispositivo cenográfico}

Já faz muito tempo desde que dos discursos se passou aos fatos. "Cercas de segurança, com arame farpado ou elétricas, detectores de movimento e blocos de concreto emergem no horizonte e se estendem pela paisagem por centenas de quilômetros" (Frye, 2019, p. 290). Para citar apenas alguns desses cenários mais conhecidos que foram radicalmente modificados nos últimos anos (a ponto de interferir até mesmo no trânsito da fauna nativa): aqueles que se estendem entre Estados Unidos e México, Espanha e Marrocos, Israel e Palestina, Índia e Paquistão, Índia e Bangladesh, Geórgia e Ossétia do Sul, Coréia do Norte e do Sul, Bulgária e Turquia, Botsuana e Zimbábue, Malásia e Tailândia ou Marrocos e Saara Ocidental (Tertrais, Papin, 2018). Não é por acaso que, como afirma Branko Milanovic (2017, p. 168-169), "onde vemos países contíguos (seja por terra ou por água) com grandes diferenças de renda, encontramos os lugares com maiores barreiras à migração". Para dar apenas um exemplo, o território fronteiriço hispano-marroquino é marcado por uma enorme desigualdade: o nível de renda espanhol é nove vezes superior ao marroquino, uma diferença tão ou mais imponente do que aquela entre México e Estados Unidos. Esse mesmo economista especifica uma sólida razão para agir dessa forma: "Em termos monetários, a cidadania dos países ricos é valiosa. Muros físicos estão sendo construídos entre jurisdições, em parte porque existe um enorme muro financeiro entre ser e não ser cidadão de um país rico" (Milanovic, 2017, p. 261).

Tais barreiras têm sido erguidas não tanto com o propósito de deter o avanço de exércitos inimigos, mas de impedir o trânsito de pessoas desarmadas, em particular/especialmente de refugiados e imigrantes. Com esse preciso objetivo são mobilizados patrulhas de fronteira, vigilância aérea, drones de última geração equipados com câmeras e todo tipo de tecnologias sofisticadas. Da mesma forma, as medidas de controle nos aeroportos são intensificadas e aperfeiçoadas: as companhias aéreas são envolvidas na verificação da idoneidade de passageiros com destino a determinados lugares, generaliza-se a exigência acerca dos passaportes eletrônicos ou desloca-se preventivamente tais controles para os locais de origem. A fronteira se torna onipresente: através de uma grande diversidade de práticas e dispositivos (inspeções aleatórias, leis de imigração, vistos, controles de divisas etc.), alguns de natureza digital e biométrica, acaba sendo inscrita "nos corpos de migrantes e levando ainda mais longe a desterritorialização das fronteiras" (Mezzadra, Neilson, 2017, p. 204).

Apesar dos enormes investimentos que exigem, nem os muros, nem as cercas, nem as demais medidas acima mencionadas conseguem impedir a continuidade dos fluxos migratórios, como mostram, por exemplo, os inúmeros cruzamentos de fronteira e estadias ilegais nos Estados Unidos ou na União Europeia que se registram todos os anos. "De uma perspectiva global, a 
única coisa que as cercas fizeram foi deslocar os problemas para outro lugar" (Frye, 2019, p. 300). As travessias se tornaram certamente mais difíceis e, na verdade, algumas cercas são regadas com o sangue de milhares de refugiados e imigrantes, mas não chegam a ser de fato intransponíveis nem dissuasivas. No entanto, muros e outros tipos de obstáculos, bem como, as políticas migratórias restritivas em geral, induzem outros efeitos perversos: os migrantes em potencial são levados a usar meios ilegais para entrar e permanecer no país desejado, o que, consequentemente, aumenta ainda mais a porcentagem de imigração irregular (Pécoud, Guchteneire, 2006, p. 81). Contudo, por mais difícil que seja, não existem medidas de controle fronteiriço que realmente sirvam para conter os sonhos das pessoas e impedi-las de entrar em um território e, ainda menos, para deter aqueles que, movidos pelo desespero, querem deixar o seu próprio país. Todos esses esforços poderiam ser considerados ridículos se suas consequências não fossem dramáticas. A indagação sobre seu significado torna-se, então, inevitável.

Os muros que foram erguidos para conter a imigração possuem, de fato, certo artifício cenográfico, uma cortina de fumaça: esses supostos instrumentos de proteção e segurança não passam de um exorcismo simbólico do medo coletivo. São objeto de um fascinante fetichismo e efeitos taumatúrgicos lhes são atribuídos. Surgem como ícones da exclusão dos outros na esperança de tranquilizar a si próprios com a falsa imagem de uma ordem reconfortante. Já adentrados no século XXI e considerando a experiência adquirida, pode-se afirmar que a maioria dos muros deve ser interpretada como uma resposta fracassada ao declínio da soberania do Estado-nação em um mundo em globalização: não são uma expressão de soberania ou poder, mas sim de impotência (Brown, 2015).

Apesar do declínio do Estado-nação em um mundo globalizado (ou, talvez, precisamente devido a isso, veja Sassen, 2001, p. 73), a medíocre perspectiva própria dessa forma ainda hegemônica de organização política determina por completo o tipo de políticas migratórias, não apenas no que diz respeito à sua concepção, mas também à sua implementação. Em outras poucas áreas do social a lógica particularista estabelecida pelos Estados territoriais soberanos é tão implacável: "Independentemente de ser grande ou pequeno, todo Estado acaba sempre se reduzindo à mesma ideia básica: a da soberania territorial, ou seja, a capacidade de agir dentro de suas próprias fronteiras tal como seus habitantes desejam e não segundo os ditames de terceiros" (Bauman, 2017, p. 66). Em um mundo amplamente interconectado, no qual os diferentes povos delinearam um emaranhado de relações complexas, a ideia de recuperar a plena soberania se apresenta, na realidade, como uma quimera: neste mundo interdependente ninguém, num sentido minimamente estrito, é propriamente senhor da sua terra. 
Apesar da aparência contrária, os muros são sinais expressivos da manifesta incapacidade dos Estados de governar as dinâmicas assimétricas desencadeadas pelos processos de globalização neoliberal, com brechas de desigualdade cada vez mais amplas. Ainda que apresentados como respostas políticas genuínas, esses muros são antes um ornamento teatral montado diante de populações cada vez mais aflitas por suas precárias perspectivas em relação ao futuro. São, ainda, uma parte distinta dessa concepção de política que a reduz a mero espetáculo. Na melhor das hipóteses, tornam-se um ícone que gera coesão em dois sentidos: mediante os muros, quem está do lado de dentro fantasia em compartilhar uma uniformidade sobre a qual construir uma comunidade fechada, enquanto, externamente, a difundida imagem de fortaleza gera coesão entre aqueles que aguardam escondidos na fronteira para cruzá-la.

Em outras palavras, para além desses efeitos performativos, os muros são instrumentos pouco ou nada operativos para deter os problemas de fundo para os quais são expressamente erguidos. No entanto, dado que sua construção continua sendo uma forma poderosa de teatralidade política, eles constituem uma obsessão para quem se alimenta eleitoralmente desse medo irracional, ainda que infundado, da "invasão" dos imigrantes. É por todas essas razões - mesmo levando em conta que a pulsão obsessiva pelos muros tenha sido anterior - que Donald Trump, que conseguiu subir ao poder, em grande parte, pela reiterada promessa de blindar a fronteira sul dos Estados Unidos e afastar os migrantes latino-americanos, tenha se tornado um farol inspirador para os partidos mais reacionários e populistas da Europa e de parte da América.

As políticas de impermeabilização das fronteiras só podem esperar a aprovação da opinião pública se antes tiverem conseguido transmitir mensagens que, para além de inculcar um considerável desprezo pelos estrangeiros, consolidem a representação das fronteiras como um fato pré-político incontestável, como um marco natural de todo Estado. É necessário que seu caráter intrinsecamente artificial se mantenha camuflado, como tantos objetos da construção social da realidade, por um intenso processo de naturalização. Isso em grande parte já foi alcançado: a entidade das fronteiras, como a dos próprios Estados, se impõe à consciência dos indivíduos e aparece diante de seus olhos como realidades dadas e irremovíveis (Boudou, 2018). Além disso, as fronteiras são frequentemente apresentadas como um fenômeno à margem da política, sobre o qual não há motivos para fazer perguntas e tampouco pensar alternativas, assim como acontece, por exemplo, no caso de um terremoto ou um tsunâmi. Se as fronteiras fossem um fenômeno natural do acaso, como aqueles que acabamos de mencionar, então elas, de fato, teriam surgido fora da vontade dos seres humanos. Mas sabemos que essa é uma ficção insustentável e que elas são o resultado de uma construção 
social e que, portanto, essas comparações não são pertinentes. Seria muito mais correto comparar as fronteiras a uma atividade sísmica induzida pelo uso de técnicas de fraturação hidráulica (fracking): um fenômeno catastrófico totalmente natural, mas causado pela intervenção humana. Tal como acontece com as sequelas produzidas pela fraturação, os efeitos perversos gerados pelas fronteiras também podem ser chamados à responsabilidade, pois não deixam de ser uma consequência dos atos humanos (Shklar, 2010).

\section{Sobre a necessidade de alternativas em matéria de migração}

É verdade que, face às dificuldades óbvias de se manter um país totalmente fechado, se opera, com frequência, um jogo seletivo de abertura/ fechamento; isso, no entanto, não impede de afirmar que a própria intenção de manter as fronteiras blindadas implica apostar abertamente em modelos de exclusão e contenção iníquos, além de inúteis. As restrições migratórias e o aumento das medidas para dificultar o trânsito fronteiriço não são neutros em termos de equidade, pois operam como dispositivos coercitivos que restringem enormemente as oportunidades das pessoas e geram importantes desigualdades distributivas. Na medida em que essas políticas se chocam com os direitos humanos e os princípios básicos da justiça, configuram uma situação injustificável em termos normativos. Para solucionar essa situação, são necessárias abordagens alternativas que forneçam uma base para a implementação de políticas que vão além da mera crítica do dano e da desigualdade de tais restrições, que sejam capazes de imaginar um mundo com limites concebidos de maneira mais permeável (Weber, 2015).

Quando os processos migratórios atuais são contemplados desde uma perspectiva global, o cenário ideal seria aquele em que todas as pessoas pudessem satisfazer suas necessidades básicas em seu local habitual de

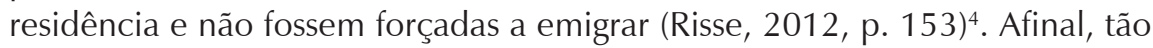
básico quanto o direito de emigrar é o direito de não ter que emigrar e poder permanecer no próprio país (Oberman, 2011). No entanto, a realidade do nosso mundo pouco se parece com esse cenário ideal. Há muitas, demasiadas, pessoas que não conseguem satisfazer as necessidades mais básicas em seu país e muito menos seguir seus planos de vida com dignidade. Alguns milhões, todos os anos, tentam se deslocar para outro país em busca de um padrão de vida decente para si e suas famílias (IOM, 2019). Em alguns casos, enfrentam qualquer perigo e sacrificam o pouco que têm para poderem ingressar no território dos seus sonhos.

4 Este horizonte é muito semelhante à visão de John Rawls (2001) sobre a anomalia que, segundo ele, representa o fenômeno migratório: a necessidade de emigrar desapareceria se a sua "utopia realista" já fosse uma realidade, isto é, se a sociedade internacional fosse, toda ela, constituída por "sociedades bem ordenadas". 
Cada vez mais pessoas abandonam suas terras contra a sua vontade por se verem expulsas de seus locais de origem. Não raramente, elas são forçadas a arriscar suas vidas através de deslocamentos perigosos. É o que acontece com aqueles que vivem em lugares que, nas últimas décadas, desertificaram, tornaram-se planícies inundadas ou que vivem em terras devastadas pela violência (Sassen, 2017); mas, também com aqueles que vivem em países relativamente prósperos e que têm seus empregos vitalícios extintos (devido à desindustrialização, robotização ou realocações), os benefícios sociais subtraídos ou que as aposentadorias parecem estar em perigo. Para os que são prejudicados pela globalização, a migração se apresenta como uma via rápida de acesso a seus possíveis benefícios, que, ao mesmo tempo, muitos governos estão determinados a obstruir.

No entanto, há algum tempo, no âmbito internacional, o direito de sair do próprio país, o direito de emigrar foi reconhecido como um direito humano. Isso é estabelecido pela Declaração Universal dos Direitos Humanos (artigo 13.2) e pelo Pacto Internacional sobre Direitos Civis e Políticos (artigo 12.2). O que não está garantido é o direito, complementar, de imigrar, sem o qual a proclamação daquele primeiro não passa de uma falácia (Velasco, 2016, p. 292-295). É nesse cenário contraditório em torno de uma compreensão integral do ius migrandi que a flexibilização do controle fronteiriço adquire total significado. Apesar das intensas disputas acadêmicas registradas nos últimos anos, o direito à imigração ainda não faz parte de nenhuma agenda política relevante. E é exatamente essa a batalha que ainda precisa ser travada. Para isso, pelo menos inicialmente, não é uma má ideia deixar de lado a teoria ideal, um âmbito no qual as divergências costumam ser retumbantes.

Se for adotada uma perspectiva pragmática, um bom ponto de partida para questionar as rigorosas políticas migratórias predominantes na atualidade é a comprovada ineficácia das políticas de controle de fronteiras e, em particular, da construção de muros. Como diz Vargas Llosa (1996): "Melhor aceitar a imigração, mesmo com relutância, porque bem-vinda ou não, [...] não há nenhuma maneira de detê-la". É uma evidência comprovada que as políticas restritivas não atendem aos objetivos propostos de limitar a migração, adaptando seu volume e composição aos interesses e necessidades das sociedades receptoras. Entre outros motivos, os esforços não são bem-sucedidos porque a migração está estruturalmente enraizada nas economias da maioria dos países, sejam eles receptores ou emissores, na forma de remessas, mão de obra barata ou serviços domésticos. As medidas de contenção, e ainda mais nos casos de fechamento radical das fronteiras, representam uma resposta inadequada, porque contradizem dinâmicas poderosas dificilmente controláveis por qualquer governo. A esta constatação pode ser acrescentado outro argumento, de natureza igualmente pragmática, que enfatiza a considerável economia 
de gastos para as contas públicas que resultariam do desmantelamento dos dispendiosos sistemas de controle fronteiriço existentes. Esses argumentos, no entanto, não conseguem abalar suficientemente a opinião pública e muito menos impedem as práticas de tantos governos que estão convencidos de obter maiores ganhos eleitorais com suas retóricas agressivas e políticas rigorosas.

Nesse contexto, e a fim de construir cartografias mentais alternativas, torna-se cada vez mais evidente a necessidade de introduzir algum elemento de distorção no discurso hegemônico sobre políticas migratórias. Ou seja, uma ferramenta disruptiva capaz de alterar o quadro, algum tipo de proposta que rompa com a inércia e que faça repensar os dogmas rotineiros em torno da questão das fronteiras e seu papel na definição da estrutura básica da ordem global. Esta tarefa é essencial, mas é também necessária outra ainda mais árdua: não cabe implementar novas políticas sem se forjar previamente um amplo consenso que as corrobore.

Apesar das dificuldades, na esfera internacional alguns progressos foram feitos nos últimos anos no sentido de estabelecer consensos sobre como oferecer uma estrutura favorável para abordar de maneira abrangente o fenômeno migratório. A este respeito, provavelmente o passo mais encorajador é o acordo multilateral assinado em Marraquexe, em 2018, por 164 países: o Pacto Global para uma Migração Segura, Ordenada e Regular, um texto previamente acordado pela Assembleia Geral das Nações Unidas (ONU, 2018). O Pacto baseia-se em dois pressupostos básicos: o primeiro trata-se da primazia dos direitos humanos na gestão da mobilidade internacional; e, o segundo, é a consideração da migração como um fator-chave para o desenvolvimento. O principal objetivo, conforme expressa o próprio título do Pacto, não é outro senão estabelecer canais para a imigração legal e ordenada, mais especificamente: "aumentar a disponibilidade e a flexibilidade dos caminhos para a migração regular". A identificação deste propósito é correta e completamente oportuna: é crucial num momento em que os governos tendem cada vez mais a perseguir e criminalizar não apenas a migração irregular, mas também a assistência prestada pelos indivíduos aos migrantes em situação de necessidade, sem oferecer como contrapartida canais seguros e previsíveis que permitam a migração das pessoas. Se os países desenvolvidos necessitam de um número crescente de mão de obra estrangeira para tornar suas economias sustentáveis, um mínimo de bom senso exigiria que a migração não fosse dificultada, mas sim gerenciada. O Pacto certamente vai na contramão dos ventos políticos que, como observado nas seções anteriores, sopram nos países mais desenvolvidos.

No entanto, o Pacto sofre de uma grave lacuna: não é juridicamente vinculativo. Os Estados podem assim acumulá-lo no amplo repertório de acordos internacionais assinados sem serem obrigados a modificar suas 
políticas. Apesar disso, importantes países receptores já se dissociaram do texto. Essa relutância por parte de certos governos indica também que, por menor que seja o valor que tais acordos possam ter, eles sempre podem se tornar uma referência crítica para medir as políticas adotadas. Ninguém gosta de ver seu rosto feio refletido no espelho. No entanto, para forçar as mudanças preconizadas pelo acordo, seria conveniente, ou melhor indispensável, ter um órgão supranacional competente, que facilitasse os movimentos transfronteiriços e que assegurasse o efetivo respeito pelos direitos de seus protagonistas, o elo mais fraco da cadeia. O Pacto não questiona nem a soberania dos estados nem as fronteiras nacionais. Embora seja verdade que no mundo de hoje não existem condições para chegar a um acordo mais ambicioso que comprometa todos os países, também é verdade que com tais acordos nunca serão alcançados resultados verdadeiramente transformadores. A ideia de estabelecer canais regulares e seguros, que resultem também previsíveis para quem busca migrar, é uma alternativa a ser levada em consideração e que não deve ser descartada. Mas, tal como está, carece de força contestatória capaz de ocupar o debate público e criar um novo marco discursivo.

\section{Rumo à inversão do statu quo global: as fronteiras abertas}

A perspectiva dos mais afetados pela intensidade da desigualdade, da violência ou das mudanças climáticas, e que são forçados a migrar, é uma voz relevante que deve ser levada em consideração nos processos coletivos de compreensão e gestão dos movimentos migratórios. Hoje, para muitos párias da Terra, o sonho mais profundo ou, se preferir, a utopia mais atraente, já não é mudar o país em que vivem, ou seja, mudar seu sistema político e sua estrutura econômica, e sim atravessar fronteiras e mudar de país (Krastev, 2017, p. 165-166). Após o colapso das utopias sociais e dos grandes relatos de emancipação, esse novo tipo de revolução não se inspira em imagens do futuro desenhadas por grandes ideólogos, mas em imagens fornecidas por múltiplos canais de comunicação sobre a vida do outro lado da fronteira ${ }^{5}$. Os novos meios de comunicação globais tornam as desigualdades muito mais perceptíveis, não apenas no que se refere à economia, mas também à ecologia. Em um mundo transformado em uma aldeia global, as pessoas

\footnotetext{
5 Se a utopia social se tornou isto, houve, então, uma contração ou deflação considerável das expectativas. Uma vez que já não contém a representação de um regime ideal, a utopia já não precisa de se comprometer com um amanhã glorioso que sirva de estímulo: é guiada pela triste certeza de que não se pode continuar sobrevivendo sem uma mudança radical de residência. É necessário partir para evitar a catástrofe, a ruína completa. E é uma degradação do espírito utópico também em outro sentido: “O objetivo já não é conseguir uma sociedade melhor [...], mas melhorar a própria situação individual dentro dessa sociedade tão essencial e definitivamente incorrigível“ (Bauman, 2017, p. 21).
} 
comparam suas vidas não com a de seus vizinhos, mas com as dos habitantes dos países mais ricos do planeta ou com aqueles que desfrutam de um ecossistema muito mais favorável, duas situações que, embora diferentes, estão frequentemente associadas. Ao contrário do que acontecia em outras épocas, seus sonhos de uma vida melhor em outro país se chocam cada vez mais com fronteiras radicalmente fechadas ${ }^{6}$.

A tal ponto se naturalizou não somente o controle das fronteiras, mas também a construção de muros e todo tipo de obstáculos ao longo do seu percurso, "que a ideia de fronteiras abertas nos parece hoje incrivelmente rara, para não dizer terrivelmente perigosa, mesmo quando as atravessamos com uma frequência crescente" (Harvey, 2017, p. 302). Sem dúvida, uma política migratória de portas abertas estabeleceria um estado de coisas contrário ao que ultimamente estamos habituados, mas isso não significa que seja uma proposta menos viável do que outras formuladas ao longo da história para responder a conflitos reais não resolvidos e que, à época, poderiam parecer ilusórios, mas hoje fazem parte da nossa realidade social. Sem qualquer ingenuidade, vale a pena questionar se a opção oposta, defendida por abordagens auto-designadas como realistas, não resulta muito mais utópica (Pécoud, Guchteneire, 2006, p. 82). E essa pergunta não se refere exclusivamente ao fechamento completo de fronteiras e portos, à "imigração zero", tão desejada por alguns populismos de um corte chauvinista, mas também à simples pretensão de manter os fluxos migratórios sob o controle implacável dos Estados. Diante das reiteradas inconsistências geradas pela gestão política desses fluxos, a abertura das fronteiras se apresenta como uma opção razoável e digna de ser considerada. De qualquer forma, é tão ou mais realista do que o pensamento hegemônico sobre o assunto. Portanto, está na hora de levantar seriamente o debate público sobre uma política de abertura, avaliando se o equilíbrio de custo/benefício político, econômico e, acima de tudo, humano - que esta política provoca é mais ou menos favorável em relação ao equilíbrio derivado de uma política de contenção rigorosa dos fluxos migratórios.

A proposta de um mundo de fronteiras abertas constitui, em grande parte, um espelho invertido das inquietantes políticas migratórias que os Estados implementam diariamente. Em contraste com essa realidade, configura-se como um projeto utópico de pequeno porte. Não se trata de

6 Provavelmente falta uma perspectiva histórica suficiente para compreender como o controle permanente das fronteiras e, mais ainda, a sua fortificação representa uma ruptura com hábitos seculares. Conhecer a história das fronteiras e das suas funções contribui para questionar a imagem agora naturalizada dos controles migratórios como algo necessário para garantir a segurança nacional. Embora hoje em dia possa parecer estranho, considerar as migrações como uma ameaça da qual é necessário se proteger nem sempre foi a opinião dominante. Houve épocas, e não muito remotas, em que as pessoas que migravam quase não encontravam impedimentos, eram acolhidas e recebiam até incentivos (Oltmer, 2012, p. 119-120). 
moldar um mundo perfeito, um paraíso na Terra, mas simplesmente de sinalizar um caminho para evitar ou pelo menos minimizar os grandes e constantes males gerados pela obsessão de controle em que a maioria dos Estados contemporâneos está presa: seria, em última instância, uma utopia focada principalmente na prevenção dos danos causados por essa ânsia irracional de controle direcionada a excluir os desfavorecidos do planeta. Mesmo que o objetivo desejado não possa ser alcançado, o simples fato de levantar essa possibilidade já teria um considerável valor político, como argumenta Joseph Carens (2013, p. 296), o filósofo que mais contribuiu para tornar essa proposta uma ideia intelectualmente respeitável: "o objetivo do argumento das fronteiras abertas é desafiar a complacência, conscientizar-nos de como as práticas democráticas rotineiras na imigração negam a liberdade e ajudam a manter a desigualdade injusta".

A proposta desafia significativamente o pensamento hegemônico, tendo um enorme potencial para contestar os fundamentos de políticas que atualmente são consideradas inquestionáveis. Mas não pode ficar só nisso. Para não incorrer em um mero exercício de diversão intelectual, e desenvolver uma reflexão motivada por uma pretensão prática e pelo desejo de transformar a realidade social, é preciso ter cuidado com sua configuração. Em um esclarecimento prévio, é necessário distingui-la claramente da ideia de um "mundo sem fronteiras" (borderless world), que não atende às condições mínimas de viabilidade no atual contexto geopolítico. Muito mais matizada e acessível e, portanto, comparativamente mais realista, é a ideia de "fronteiras abertas" (open borders), que não questiona a atual divisão do mundo em Estados soberanos. No entanto, essa ideia para ser implementada requer alguns ajustes, dois dos quais serão mencionados a seguir.

Em primeiro lugar, a abertura das fronteiras não seria indiscriminada. Elas não desapareceriam, mas haveria uma modificação das funções reguladoras atribuídas até agora a esses dispositivos e das formas de gerenciá-las. As fronteiras persistiriam como demarcações territoriais de Estados independentes e, portanto, de áreas jurisdicionais diferenciadas. Em segundo lugar, não seria descartada a possibilidade de restrições de curto prazo ao trânsito fronteiriço em circunstâncias especiais. As autoridades estaduais teriam poderes para fechar temporariamente as fronteiras em determinadas situações, incluindo, por exemplo, o surgimento de uma grave pandemia ou a ocorrência, dentro do próprio país, de catástrofes naturais, conflitos bélicos ou situações de risco iminente de ataque terrorista. De qualquer forma, essas circunstâncias deveriam ser convenientemente avaliadas para impedir a discricionariedade do governo e evitar que a possibilidade de impor restrições conduza a limitações desproporcionais à liberdade de movimento, liberdade que, em todos os casos, deveria ser a regra geral, de tal forma que não se torne normal o que é considerado excepcional. 
Mesmo com esses esclarecimentos, não é uma proposta pacífica. Pelo contrário, questiona esse dictum supostamente realista e a expressão máxima do pensamento único de que, diante do status quo "não há alternativa" (there is not alternative). Pelo fato de geralmente se presumir que não existe uma alternativa viável para o estado atual das coisas, por mais que a maioria das pessoas o considere injusto, isso deve ser atribuído, no plano teórico, à predominância de uma compreensão fetichista das condições sociais (Honneth, 2017, p. 22), algo que, no plano mais prático, se traduz em uma clara tendência ao conformismo.

As fronteiras abertas são hoje pouco mais do que uma ideia programática que talvez possa servir de guia naquela navegação em que toda a humanidade está embarcada, uma ideia ambiciosa diante da qual cabe expressar um ceticismo prudente perante a situação real do mundo. Se não lhe forem atribuídas virtudes milagrosas, inclusive evitando sugerir que sua implementação provocaria a superação de todos os males e injustiças do mundo, ela tem, no entanto, o valor inestimável de alimentar o debate na esfera pública mundial e contrariar tendências autárquicas claramente hegemônicas.

\section{Bibliografia}

ABIZADEH, Arash. Democratic Theory and Border Coercion. Political Theory, v. 61, p. 37-65, 2008.

ANDERSSON, Ruben. Illegality, Inc. Oakland: University of California Press, 2014.

BALIBAR, Étienne. ¿Qué es una frontera? In: BALIBAR, Étienne. Violencias, identidades y civilidad. Barcelona: Gedisa, 2005, p. 77-86.

BAUMAN, Zygmunt. Extraños llamando a la puerta. Barcelona: Paidós, 2016.

BAUMAN, Zygmunt. Retrotopía. Barcelona: Paidós, 2017.

BOUDOU, Benjamin. Le dilemme des frontières. Paris: Éditions EHESS, 2018.

BREZCER, Jan. Internationale Freizügigkeit als Menschenrecht. Frankfurt: Campus, 2018.

BROWN, Wendy. Estados vallados, soberanía en declive. Barcelona: Herder, 2015.

CORTINA, Adela. Aporofobia, el rechazo al pobre. Barcelona: Paidós, 2017.

DELGADO, Pedro Pablo. Apátridas, refugiados y migrantes. Lima: FCE, 2013.

EATWELL, Roger; GOODWIN, Matthew. National Populism. London: Pelican, 2018.

FOUCHER, Michel. L'obsession des frontières. Paris: Terrin, 2012.

FRYE, David. Muros. La civilización a través de sus fronteras. Madrid: Turner, 2019. HARVEY, David. El cosmopolitismo y las geografías de la libertad. Madrid: Akal, 2017. HABERMAS, Jürgen. Facticidad y validez. Madrid: Trotta, 1998.

HONNETH, Axel. La idea del socialismo. Buenos Aires / Madrid: Katz, 2017.

IOM. Migration Data Portal. 2019. Disponível em: <https://migrationdataportal. org/?i=stock_abs_\&t=2017>. 
KRASTEV, Ivan. Un futuro para las mayorías. In: ALBA RICO, Santiago et alii (eds.). El gran retroceso. Barcelona: Seix Barral, 2017, p. 151-170.

LAKOFF, George. No pienses en un elefante. Madrid: Editorial Complutense, 2007. MEZZADRA, Sandro; NEILSON, Brett. La frontera como método. Madrid: Traficantes de Sueños, 2017.

MILANOVIC, Branko. Desigualdad mundial. México: FCE, 2017.

MILLER, David. Immigration: The Case For Limits. In: COHEN, Andrew; WELLMAN, Christopher (eds.). Contemporary Debates in Applied Ethics. Oxford: Blackwell, 2005, p. 193-206.

MILLER, David. Strangers in Our Midst. Cambridge, MA: Harvard U.P., 2016.

OBERMAN, Kieran. Immigration, Global Poverty and the Right to Stay. Political Studies, v. 59, n. 2, p. 253-268, 2011.

OLTMER, Jochen. Globale Migration. Geschichte und Gegenwart. Stuttgart: Beck, 2012.

Organización de las Naciones Unidas. Pacto Mundial para una Migración Segura, Ordenada y Regular. 2018. Disponível em: <http://www.un.org/es/conf/ migration/global-compact-for-safe-orderly-regular-migration.shtml>.

PÉCOUD, Antoine; GUCHTENEIRE, Paul. International Migration, Border Controls and Human Rights. Journal of Borderlands Studies, v. 21, n. 1, p. 69-86, 2006.

RAWLS, John. El derecho de gentes. Barcelona: Paidós, 2001.

RISSE, Mathias. On Global Justice. Princeton: Princeton U.P., 2012.

RODIER, Claire. El negocio de la xenofobia. Madrid: Clave Intelectual, 2013.

SASSEN, Saskia. ¿Perdiendo el control? La soberanía en la era de la globalización. Barcelona: Bellaterra, 2001.

SASSEN, Saskia. La pérdida masiva de habitat. Iglesia viva, n. 270, p. 11-38, 2017. SHKLAR, Judith. Los rostros de la injusticia. Barcelona: Herder, 2010.

TERTRAIS, Bruno; PAPIN, Delphine. Atlas de las fronteras. Madrid: Cátedra, 2018. VALLET, Élisabet; DAVID, Charles-Ph. Introduction. Du retour des murs frontaliers en relations internationales. Études internationales, v. 43, n. 1, p. 5-25, 2012.

VARGAS Llosa, Mario. Los inmigrantes. El País, 25.08.1996. Disponível em: < http:// www.elpais.com/articulo/opinion/ESPANA/TERCER_MUNDO/inmigrantes/ elpepiopi/19960825elpepiopi_4/Tes>.

VELASCO, Juan Carlos. El azar de las fronteras. México: FCE, 2016.

VELASCO, Juan Carlos. Healing the Scars of History: Borders, Migration, and the Reproduction of Structural Injustice. In: VELASCO, Juan Carlos; LA BARBERA, Maria Caterina (eds.). Challenging the Borders of Justice in the Age of Migrations. Cham: Springer, 2019, p. 17-36.

WALZER, Michael. Las esferas de la justicia. México: FCE, 1993.

WEBER, Leanne (ed.). Rethinking Border Control for a Globalizing World. London/ New York: Routledge, 2015.

YPI, Lea. Justice in Migration: A Closed Borders Utopia?. The Journal of Political Philosophy, v. 16, n. 4, p. 391-418, 2008. 